\title{
Abstract \\ Particle Hunters. Special Relativity as a Tool for Discovery in Particle Physics ${ }^{\dagger}$
}

\author{
Lorenzo Galante
}

check for

updates

Citation: Galante, L. Particle Hunters. Special Relativity as a Tool for Discovery in Particle Physics.

Phys. Sci. Forum 2021, 2, 18

https://doi.org/10.3390/

ECU2021-09325

Academic Editor: Magdalena

Kersting

Published: 22 February 2021

Publisher's Note: MDPI stays neutral with regard to jurisdictional claims in published maps and institutional affiliations.

Copyright: (c) 2021 by the author. Licensee MDPI, Basel, Switzerland. This article is an open access article distributed under the terms and conditions of the Creative Commons Attribution (CC BY) license (https:/ / creativecommons.org/licenses/by/ $4.0 /)$.
Teaching and Language Laboratory, Department of Apllied Science and Technology, Politecnico of Torino, Corso Duca degli Abruzzi, 24, 10129 Torino, Italy; lorenzo.galante@polito.it

+ Presented at the 1st Electronic Conference on Universe, 22-28 February 2021; Available online: https:/ / ecu2021.sciforum.net/.

\begin{abstract}
Special relativity is a fundamental tool for the analysis of collision events in particle physics. This provides the opportunity to create educational environments in which interactions between theory and experimental data occur, an opportunity whose potentiality is worth exploring. An interactive application to analyze a collision between particles is presented as a tool that opens a mystery students must solve using special relativity as an inquiry tool. As in a Role Play Game, students are introduced into an environment they have to empathise with. They are asked to play the role of a particle physicist, to analyze a collision between a pion and a helium nucleus and to solve the mystery that arises from their analysis: momentum seems not to be conserved! Will they have to dismiss the conservation law or start the hunt for an undetected particle responsible for the missing momentum? As in many Role Play Games, the participants have special powers or attitudes. Here, the special power comes from Einstein's energy-momentum-mass relation, which will be the magic wand leading students toward the solution of the puzzle. "Particle Hunters" is an educational environment designed to promote a deeper understanding of specific aspects of special relativity and to foster empathy and critical thinking throughout the learning process.
\end{abstract}

Keywords: teaching; special relativity; Modern Physics; Role Play Game; Einstein

Supplementary Materials: The video presentation is available online at https:/ / www.mdpi.com/ article/10.3390/ECU2021-09325/s1.

Institutional Review Board Statement: Not Applicable.

Informed Consent Statement: Not Applicable. 